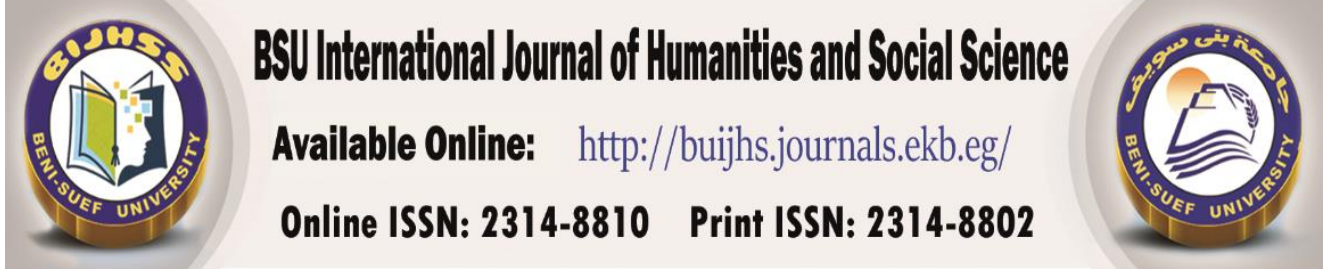

\title{
A great cosmic phenomenon in the heritage
}

\section{of the ancient Egyptians}

\author{
Dr_Mona Zoheir El-Shaieb
}

Associate Professor_Department of Egyptology - Faculty of Archaeology - Cairo University

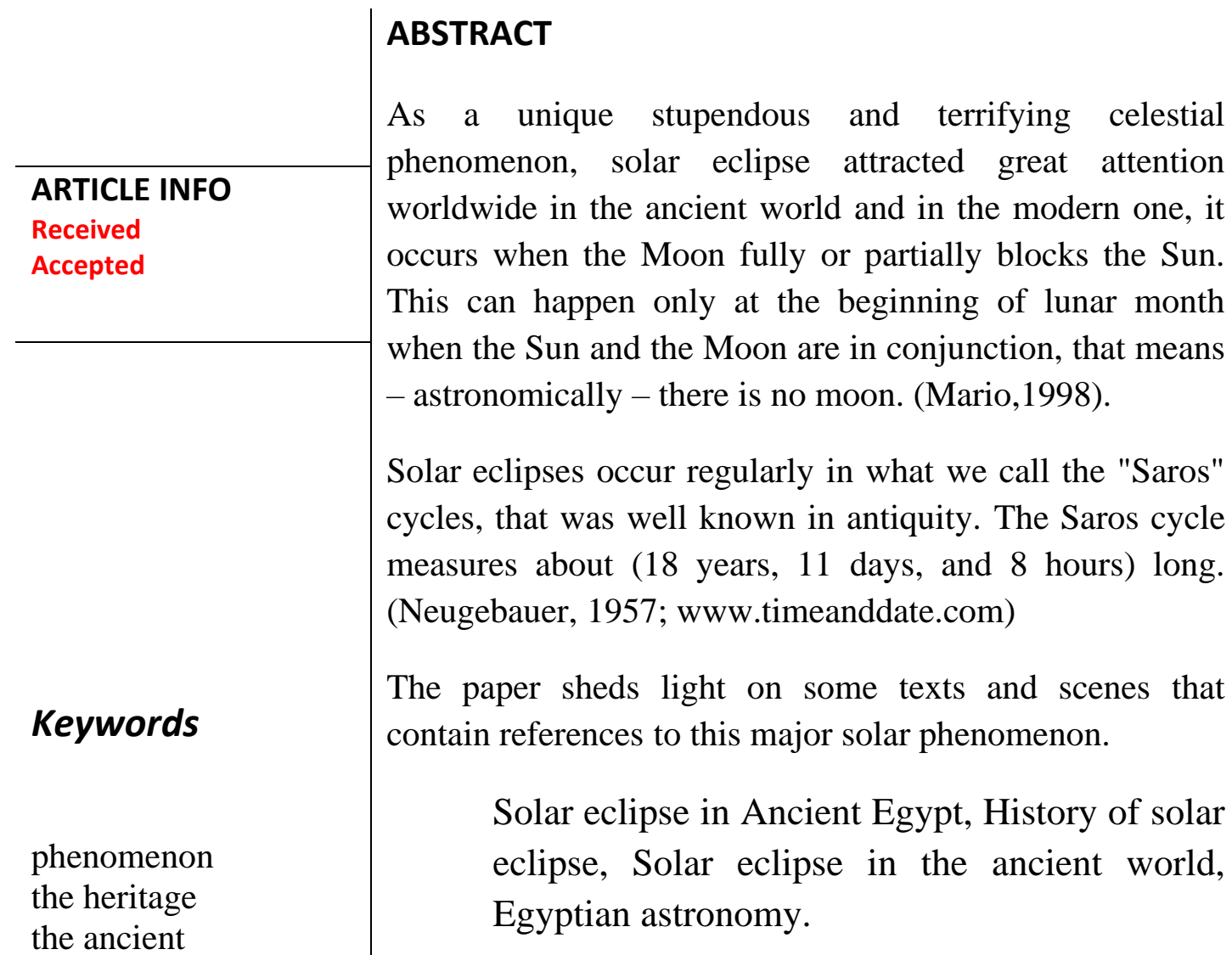

Egyptians 


\section{Introduction}

Despite the important role that the Sun played in the daily life and religion of the ancient Egyptians, direct references to solar eclipse were not mentioned in an early era.

It seems uncertain, to some scholars, how did the Egyptians describe a solar eclipse since their astronomical records written on papyrus have not survived, however, external sources confirmed the Egyptians' possession of an accurate knowledge of solar and lunar eclipses. (Brewer, 1991 ; McMurray, 2003)

In the history of cultural astronomy, virtually every ancient civilisation viewed the sudden chewing-up of the Sun as a bad omen."Eclipse" itself is derived from the Greek word ekleipsis "abandoned". (Park, www.academia.edu)

It is clear that the Egyptians, like most ancient cultures, also associated the observation of this solar phenomenon with the occurrence of misfortunes; since they used to cloudless, clear skies, the sudden appearance of stars during the daytime would have been terrifying.

Perhaps, at the base of their fear is the fact that the eclipse seems to break, to some extent, the order of the celestial vault, or of mAat, which could be threatened by strange events such as eclipses. (Lull, Arqueoastronomia).

Throughout the year, the temple priests the "hour watchers" measured the shadow of the Sun to determine the prayer times and the beginning of religious festivals. (Park, www.academia.edu)

They preserved 49 books of Thoth, at least four of them dealt with astronomical subjects, all were described by Clement of Alexandria who noted that one book explained the "the conjunction of the Sun and 
Moon and the variation of their lights". It is evident that the ancient Egyptian astronomers could and did predict eclipses.

Greek writers admired the astronomical knowledge of the Egyptian priesthood and confirmed repeatedly its remarkable ability in predicting solar eclipses, in a way that filled in so many gaps caused by lack of evidence. (science.ksc.nasa.gov)

\section{How was the eclipse explained in Egyptian heritage, and were there any gods connected with it? Examples:}

\subsection{Pyramid Texts}

The oldest Egyptian religious writings and primary source for studying the thoughts and believes of the ancient Egyptians, they were first inscribed in the pyramid of Unis, although, most of these texts are undoubtedly older with few exceptions.

Many utterances contain clear references to solar eclipse in different terms especially those relating to: The conflict between Horus and Seth, and the roll of Thoth in healing the injured eye - The swallowing of the eye of Horus - Sunlight blocking - The fallen of the sunshine into the inundation - The black hole of the sky - The reappearance of the sun against an evil serpent - Threatening the monsters of the sky to lie down .... etc.

PT utt. 204:" ..... for they have swallowed the bright eye of Horus which is in On ...."

PT utt. 467: "I have reached the sky as a locust which hides the Sun" (often manifested as a dung-beetle).( Faulkner, 1969) 


\subsection{The Prophecies of Neferti}

The text is preserved on papyrus Leningrad $1116 \mathrm{~B}$ dating from the $18^{\text {th }}$ dynasty, but the text itself relates the conditions that prevailed before the accession of Amenemhat I:

"The Sun disc, covered, shines not for people to see, one cannot live when clouds conceal it, all are numb from lack of it".

"Ra .......... shines, that the hour may be told, but no one knows when noon occurs, for no one discerns his shadow, no man is dazzled by seeing [him], there are no one whose eyes flow with water, because he is like the moon in the sky, ....... [then] his rays are in (men's) eye as on former occasions". (Simpson,1972)

\subsection{The Admonitions of Ipuwer (Papyrus Leiden I 344 recto)}

The text is originally dated to the late $12^{\text {th }}$ Dynasty (1991-1803 B.C.), written in Hieratic. It contains the phrase "The land is without light" (IP 9:11), perhaps as a reference to a total solar eclipse. (Gardiner,1909; www.ancient-origins.net)

\subsection{The myth of Apep}

Darkness, the enemy of light, was symbolized by the Apep serpent "the Great Worm" which was depicted as a huge serpent. Although he was believed to have existed since primeval times, texts did not mention his name until the Middle Kingdom. It rose up each night in the realm of Duat to destroy the sun bark. Occasionally it issued forth in daylight, at dreaded eclipse it seemed to achieve temporary triumph. (www.ancientegyptonline.co.uk)

According to one legend, Apep would hypnotize the sun god and all his crew, except Seth who would stop the serpent by piercing his body with a great lance. In some texts, Apep would enclose the boat of Ra in his massive coils or cause it to be flooded with the waters of the 
underworld. In other texts Apep was equivalent to Seth and would be defeated by an army of gods and goddesses. (www.ancientegyptonline.co.uk)

To help maintain mAat (order), if Apep swallows the sun god, the dead would cut a hole in the body of the serpent to help the sun god free himself. If they failed, the universe would be immersed into darkness.

As an evil spirit Apep has also been connected with many terrifying events such as undue darkness caused by solar eclipses, storms and earthquakes. He was related with the cold, dark and dangerous place in the northern sky. (Troy,2017)

This serpent of chaos and death, who could never be entirely vanquished, was the major enemy of the sun god Ra, he was a malicious force trying always to devour the sun disc, but in the end, $\mathrm{Ra}$ always defeats him, and the sun would shine again. (www.vox.com)

From this point, the ancient Egyptian myth of the snake Apep that attacks the boat of the Sun god trying to swallow the Sun's disk is believed to be a typical ancient Egyptian interpretation of a solar eclipse. (www.wral.com; www.bibalex.org)

\subsection{The tomb of Meryre I}

In the tomb of Meryre I the high-priest of Aton (TA 4), at Tell elAmarna, there is a unique and unusual solar scene (Fig.1): several groups of multicolored arcs were inscribed between the Aton disk and its rays resembling the wide collars worn by royalty, it was supposed, to some authors, to represent the rays of the rising sun shining through clouds. (McMurray, 2003)

According to Davies it may be a sign of the evening sacrifice performing by the pharaoh (Davies,1903), but, actually it seems so unusual to portray the setting sun in such a way, and why would the 
ancient Egyptians portray the sun in an evening sacrifice scene in the first place?

That scene was believed, in McMurray's opinion, to portray a total eclipse, and its most significant feature is the hindering of the sun's rays heading towards Earth: the two main groups of multiple arcs shown in the scene must match with the shadow bands seen just before and after totality, and their distinguish shape looks like the "diamond ring" effect (which occurs at the beginning and end of totality during a total solar eclipse) (McMurray, 2003; https://brainly.in/question/8889718 )

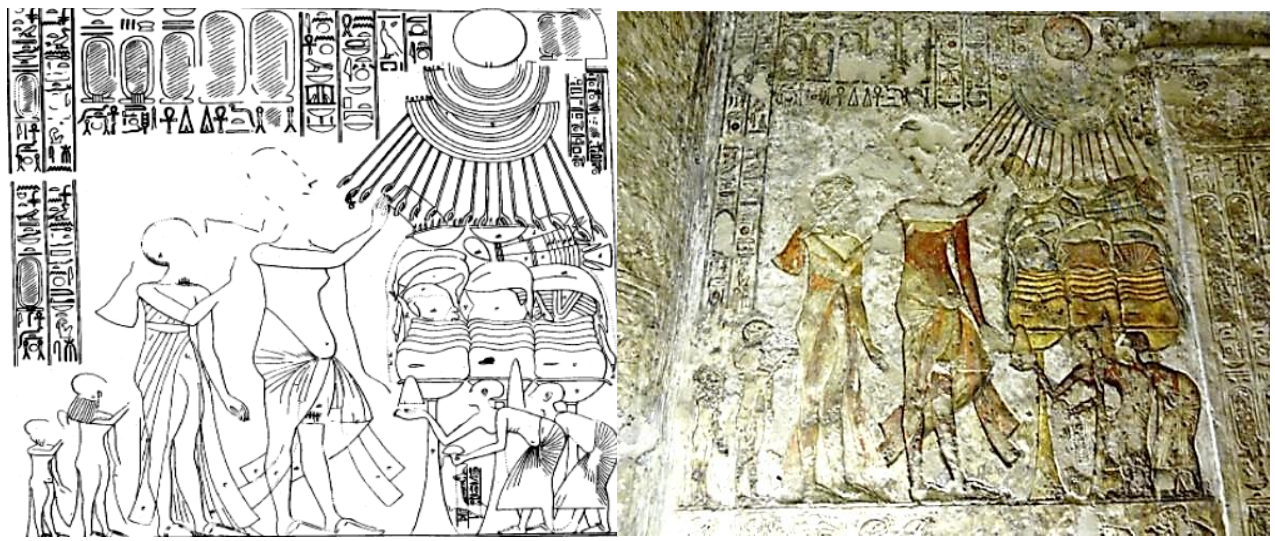

Fig. 1: The Tomb of Meryre I, s. wall, e. side

The Royal Family Making Offerings to Aton. (after McMurray,2003)

The inscription on the tablet of Ugarit (KTU 1.78) that was found in 1948, was interpreted in 1970 as the earliest documentation of a total solar eclipse, although the eclipse was not total in Ugarit itself. (McMurray, 2003)

The date of this eclipse was May 31375 B.C., and since it was close to Akhenaten's accession, according to some scholars, it seemed possible that this might be the eclipse that influenced the heretic pharaoh. (McMurray, 2003; Muller \& Stephenson,1975) 
If Akhenaten became king in 1353 B.C. the total solar eclipse of May 141338 B.C., would be occurred in his $15^{\text {th }}$ year, according to the NASA web page its location was in the Libyan Desert $\left(23.8^{\circ} \mathrm{N}\right.$, $23.4^{\circ} \mathrm{E}$ ), and as the eclipse' path of totality passed through Akhet-Aten, it was perhaps the one registered in Meryre's tomb, the eclipse lasted for $\left(6 \frac{1}{2}\right.$ minutes), and the band of totality covered an area about 256 $\mathrm{km}$, accordingly it would be witnessed in Akhet-Aten. (McMurray, 2003)

Aton carried the title "Lord of Jubilees" in the Amarna period this may only refer to the daily sunrise, which deserves thankful worship. In the point of view of McMurray "a total eclipse of the sun could be regarded as celebration of a heb-sed in heaven". (McMurray,2003), but how could a terrifying phenomenon be regarded as a celebration of any kind?

\subsection{The book of coming forth by day}

Chapter 17 in the book of coming forth by day (has, as its textual roots, utterance $335 \mathrm{CT}$ ):

Iw mH.n.i Wsir sS Any mAa Vrw n.k wDAt m-Vt hAbQ.s hrw pwy $n$ aHA rHwy pw ........ in grt +Hwty iri nn $n$ m DbA.fy Ds.f $m$ sTsi.n.i Snw $m$ tri $n$ nSny..... in(i). n.f $s \mathrm{n}$ anV wDA

"I filled the WDAt eye for you, the scribe Osiris Ani, true of voice, after it had been injured on that day of the fight of the two combatants ...... Now, indeed, it was +Hwty who did this with his own fingers, when I lifted up the hair at the time of rage ........ he brought it to life, prosperous". 
A reference to solar eclipse could be included in the word $m h$ of the WDAt eye after it had been injured $h 3 \mathrm{~b} K \mathrm{~s}$. s as a result of the fight between Horus and Seth.

Because solar eclipses occur when the moon blocks the light of the sun, we should not be surprised when the texts refer to Thoth (the moon) as the saver of the WDAt eye, and the restorer of the sun's light after the disorderly act of Seth that has momentarily upset the harmony of the universe. (Mario,1998)

Moreover, Thoth cures the eye with his fingers, the metaphor of fingers is used to convey the degrees of totality of the solar eclipse on the eye of Horus. Obviously during a solar eclipse Thoth personifies the moon and his movements, while Horus personifies the sun. (Mario,1998)

We can consider Thoth, the moon, as the major actor in the conflict between Horus and Seth, as he is both partly responsible for the injury to the eye (the sun), yet he is the healer who restores the eye to its previous condition. Astronomically speaking it is the movement of the moon that causes solar eclipse and restores the sun thereafter, "this scientific fact is beautifully depicted by the ancient Egyptians through the cosmic activity of Thoth". According to Mario the image of solar eclipse recorded in chapter 17 of "the book of coming forth by day" can strongly be assumed to express a historical continuity of eclipse observation that stretched back to the earliest periods of the ancient Egyptian civilization. (Mario,1998)

\subsection{Sp. 1112 - 885 , coffin texts}

Sp. 1112: This spell was written on eight coffins (De Buck \& Gardiner,1961)

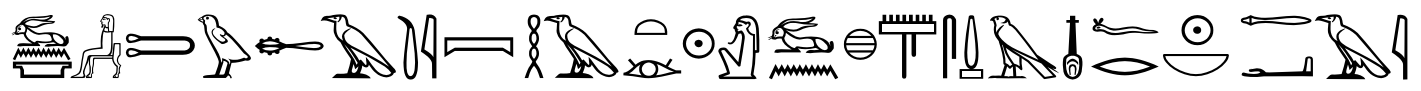



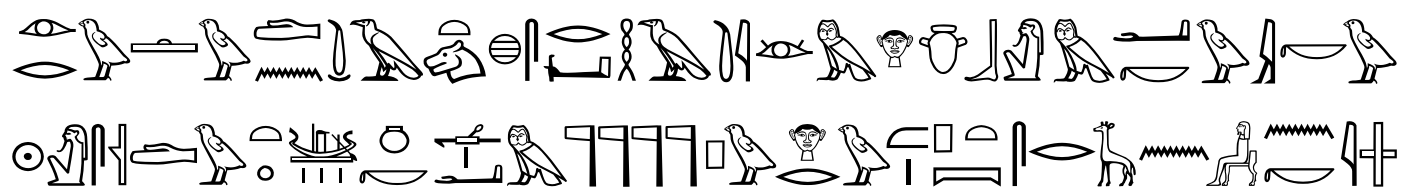

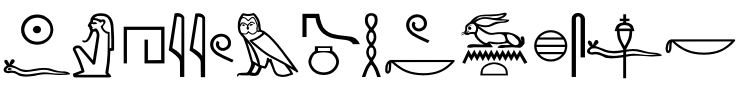

wh Tw XAti HAt Ra wnx sDA ar nfr ra no aA irw wdn At xsr HAti $m$ Hr ib nTr mk w ii.kwi Ra sqdwt ink wa $m 4$ nTrw (i) pw Hrw gs (n) pt sr.n.i n.k imi itn.f (ra.f) hny m nwH.k wht xsf.k

"O storm, you the cloudy one! Re is covered but Horus proceeds happily every day, (even he) the great shape and weighty of striking power, who dispels cloudiness with his fiery breath". (Faulkner,1978)

Sp. 885: "Re is bitten by the naw snake - and vice versa ... Fall, you snake which Atom bitten ... the viper is in the sky". (De Buck \& Gardiner,1961)

The naw - Snake bite causes blindness and affects visual nerves.

\subsection{Sp. 135, book of the dead}

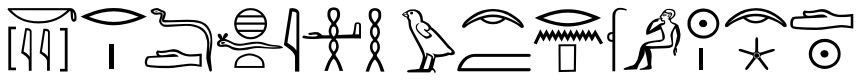

ky r Dd xft iaH $m$ rnp ra 1 Abd

"Another spell is recited at the new moon on the first day of the month".

Faulkner considered this spell as removing " blurriness of sun god's eye with his fiery breath". (Faulkner, 2000)

For Davis the fiery breath is a possible indication of the corona flash and of the "Bailey's Beads" phenomenon (flashes of light that occur at the moment of totality), accordingly the given translation was 
"he opens the cloud .............. he makes himself free ". (after Smith, 2007)

Hodel-Hoenes considered spell 135 to be protectable contra a solar eclipse that occurs at the new moon. (Hodel-Hoenes, 2000)

Smith discussed some inscriptions appeared on a number of artifacts from the west bank of Luxor related to spell 135 of the book of the dead, these inscriptions were traditionally interpreted by scholars as references to blindness or of spiritual darkness. According to him these artifacts register a total solar eclipse that was witnessed and was considered a punishment or omen, consequently it had a religious interpretation. (Smith,2007)

Several tombs from Deir el-Medina dated to the $19^{\text {th }}$ Dynasty contain a spell comprise a text and/or a vignette showing 4 or 5 deities, a disk and 6:8 stars on a dark background, according to Shaw a total solar eclipse synchronizes this period ( $19^{\text {th }}$ Dynasty) covering Thebes and corresponds to the $22^{\text {nd }}$ year of the reign of Ramses II: (Jul 27 $27^{\text {th }}$ 1258, Thebes, 3 min $12 \mathrm{sec}$ ). (Shaw, 2000)

Spell 135 also occurred on some papyri, as Papy. Neferrenpet dated to the beginning of the reign of Ramses II with both vignette / text, other papyri contain this spell dated to the $21^{\text {st }}$ dynasty, the frequent expression found in these texts was "seeing it get dark during daytime". (Smith, 2007)

\section{Selected texts from stelae, ostraca and graffiti: 2.9}

\section{A. From Deir el-Medina:}

Stela Bankes No. 6 \& TT 1: belongs to Iy-neferti, wife of Sennedjem, Černý translated the text as " you caused me to behold darkness in the daytime". (after Smith,2007) 
But it is still not clear if a solar eclipse was depicted in TT1 or not, although what looks like a sun disk was drawn on a starry sky. (www.ancient-origins.net)

Stela BM 374 \& TT 218: it shows the scribe Amonnakhte kneeling before Meretseger, Gunn's translation of the text was "you caused me to behold darkness in the daytime". (Gunn,1916 ; Smith, 2007)

\section{Stelae BM 589 \& Turin 50058 \& TT5:}

show the worker Neferabu prays to Ptah, Gunn's translation of the inscription was "he caused me to see darkness in the daytime". (Gunn,1916 ; Smith, 2007)

Stela Turin 50058: belongs to Neferabou, who made a vow to Meretseger, Gunn's translation of the inscription was "I was in her hand by night as by day". (Gunn,1916 ; Smith, 2007)

Stela Turin 50046: it shows Neferrenpet and his wife (perhaps his sister) their daughter worshiping +Hwty. Gunn's translation of the inscription was "you cause me to see darkness you make". (Gunn,1916 ; Smith, 2007)

Stela Turin 50050: was dedicated by Heria to Ahmose Nefertari, Tosi and Roccati translated the inscription as "I may see the darkness you create". (after Smith, 2007)

Stela Turin 50051 \& TT290: Irynefer's wife "Nebtnuhet" worships opd or +Hwty. Gunn's translation of the inscription was "you caused me to behold darkness you make". (Gunn,1916; Smith, 2007)

Stela Turin 50052: shows the draughtsman Pai worships Khonsu, it was in honor of his mother Wadjetronpet, Ipuy's wife. Gunn's translation of the inscription was "you caused me to behold darkness you make". (Gunn,1916 ; Smith, 2007) 
TT 265: The tomb of the scribe Amenemopet.

TT 356: The tomb of the worker Amenmuwia.(Smith, 2007)

\section{B. Other references from the New Kingdom:}

Stela JE 37463 - Cairo Museum: it belonged to Huy, Viceroy of the king in Nubia under Tutankhamen, Rowe's translation of the text was "I see darkness in the daytime by your making".

Furthermore, there is another reference to darkness in Huy's tomb (TT40), that was translated by Gardiner as "May your sight be clear in the path of darkness". Usually, it has always been assumed that darkness is a reference to the underworld, however, there is a possibility that the intention was a precaution against seeing the same terrifying solar phenomenon again in the afterlife. (Davies \& Gardiner,1926 ; Smith, 2007)

It appears that these texts represent prayers and invocations addressed to gods and royalty; with no direct mention of celestial phenomena. It is always our modern explanation of the words which made us suppose that "blindness" or "darkness" should be taken literally or spiritually. (www.ancient-origins.net)

All of these texts contain formulas which seem to describe darkness at daytime, and also the determinative of "night" or "darkness", that was used in the New Kingdom for the first time, except Stela Cairo JE 37463 , but probably owing to the lack of space as it was relatively small. (Smith, 2007)

Terms as darkness, cloudiness, storm, covering / uncovering etc. were very likely used by a witness of the extraordinary phenomenon of solar eclipse, as during a total solar eclipse the sky may darken for a 
while and the atmosphere becomes cooler. (Smith, 2007 www.history.com)

Solar eclipses occurred around this time that corresponds to standards of depth and location:

Eclipse (B.C.): Oct. $17^{\text {th }} 1328$, Location: Aniba - Karnak, Duration: 3 $\min 29 \mathrm{sec}$ (not total).

Eclipse (B.C.): Oct. 17 1309 , Location: Aniba - Karnak, Duration: Very brief (not total). (Smith, 2007)

Ostracon Cairo 12202: it was found in Sheikh 'Abd el-Qurna, on the west bank of Thebes, written in hieratic, Posener translated the text as "you caused me to see day like night". (Posener, 1975 ; Smith, 2007)

According to Shaw it can be dated about 1550 B.C.- 1425 B.C., solar eclipses occurred around this time that corresponds to standards of depth and location: (Shaw, 2000 - Smith, 2007)

\section{Eclipses (B.C.)}

Apr $20^{\text {th }} 1523$

Jun $1^{\text {st }} 1478$

\section{Location}

Thebes

Thebes

\section{Duration}

$4 \min 34 \mathrm{sec}$

$3 \min 23 \mathrm{sec}$

Grafitto Pawah: in the tomb chapel of Pere (TT 139) at Thebes and was written in hieratic. The registered date was: the $10^{\text {th }}$ of the $3^{\text {rd }}$ month of AVt - year 3 of the reign of Smenkhare. Gardiner translated the text as "you caused me to behold darkness by day". (Gardiner, 1928 ; Smith, 2007)

Solar eclipses occurred around this time that corresponds to standards of depth and location: (Smith, 2007) 
Eclipses (B.C.)

May $14^{\text {th }} 1338$
Location

Akhetaten - Thebes

\section{Duration}

$5 \min 48 \sec$ (not total)

\subsection{Stela of Naukratis}

The $4^{\text {th }}$ Century B.C. black granite "Stela of Naukratis" was discovered in 1899 at Kom Geaaief - Etai el- Barood.

In the Late Period, during the morning (10.13 local time according to Brady), an Annular Solar Eclipse in Scorpio would have been ideally observed in a narrow-banded pathway of the Delta near Alexandria. The month and year date (early November 380 B.C. in conventional dating) for this New Moon coincided with the start of the new Dynasty 30, when Nectanebo I ascended the throne of Egypt. (Park, www.academia.edu)

According to Park there were references in the inscription to solar eclipse: the apparent looking equal sized Sun and the Moon melt into one sacred geometry circle, and the text of columns 5 and 6 , when Nectanebo made it clear that he was swayed by the wisdom of the temple priests noting that he "consulted with prophets, and was not deaf to their words concerning the path of the god" (i.e. ecliptic).

Nectanebo I turned what had previously been seen as an ill omen, i.e. an eclipse, into a sign of unquestioning divine approval of his accession to the throne of Egypt, and his relatively long and successful reign.

The inscriptions provide no clear evidence that any pharaoh authorised the recording of any meaningful date, which might be interpreted as Egyptian "eclipse astrology". (Park, www.academia.edu)

\subsection{Papyrus Berlin 13588}


This document comes from Herakleopolis Magna (Ehnasia), it was written in demotic, because of its very cursive writing, which is typical of the late Greco-Roman era, it must be dated to the first century B.C.. In the third column we read: "Heaven swallowed the solar disk when he was taken to the embalming room, in which the body of the king Psamtic was to be prepared for burial". In The first sentence there is a reference to a total solar eclipse:

am tA pt $p A$ itn, the verb am has several meanings: "swallow", "choke", "drink", "devour", "suck", "absorb", etc. (Lull, Arqueoastronomia)

In an older inscription, in the well-known Chronicle of Prince Osorkón, of the Third Intermediate Period, (the $8^{\text {th }}$ century B.C.), which was written in hieroglyphs on the inner walls of the Bubastis door at Karnak, we find again a similar reference to an eclipse of the Sun:

jr m-xt HAt-sp 15 Abd 4 Smw sw 25 xr Hm n jt Sps nTr HqA WAst / nn am pt jaH nSnj xpr $m$ tA pn

"Subsequently, in the $15^{\text {th }}$ year, the $4^{\text {th }}$ month of Shemu, day 25, under the majesty of this honorable father, the god who rules Thebes, I (though) Heaven did not swallow the Moon a great misfortune became on this earth".

Evidently, in both texts we can conclude that the verb am can be translated as "swallow", "devour", etc., but always in the sense of eclipsing. ( Lull, Arqueoastronomia)

In another mythological text most probably from the same era we read: "Retire like a crocodile so that the Sun does not eclipse (?) (...) so that the sky does not swallow the Moon". The verb "eclipse"(?), knH, in the point of view of some scholars, whose noun is qnHw, and the 
verb "swallow", am, although this verb is not used only for the astronomical phenomenon, as with $\mathrm{knH}$ "eclipse", the truth is that the context in which it appears does not leave any doubt. (Lull, Arqueoastronomia; Schott,1929-1939 ; Smith, 2007)

In papyrus Berlin 13588 it is said that the eclipse of the Sun coincided with the death of the king Psmatic, because it occurred when he was in the embalming room, wabt, where his body should remain seventy days, the referred eclipse is that of September 30, 610 B.C., the death of the pharaoh, since the corpse was still in the embalming room, should have occurred between the months of August and September of that year. (Lull, Arqueoastronomia)

\subsection{The Zodiac of Dendera}

Dating the Zodiac of Dendera using planetary motions, Auberg noted that two disks were depicted in the constellation of Pisces, with no doubt one of these depicts the moon, while the other contains a WDAt eye. The association of the disks with a solar eclipse was confirmed by the presence of the god of the moon Thoth as a baboon with its tail cached by a goddess in a very interesting image probably indicates, according to Auberg, that the goddess prevents the moon from covering the sun (Fig. 2). (Auberg, 1995)

He calculated that a nearly total solar eclipse occurred on March 7, 51 B.C. in Dendera. The depiction of the disk with the WDAt eye in this curious combination refers to the eye of Horus which he lost in the conflict with Seth and assumes that the myth may have originated in an early observation of a solar eclipse. (Auberg, 1995) 


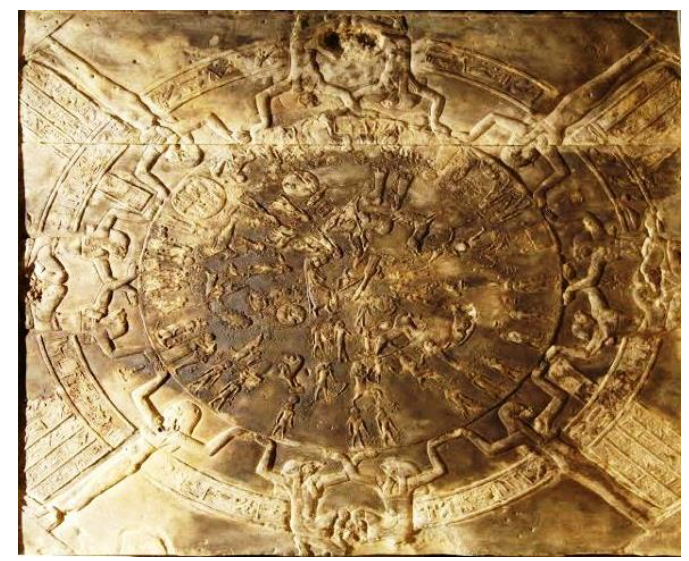

Fig. 2: Dendera Zodiac

(https://www.louvre.fr/en/oeuvre-notices/zodiac-dendera)

\section{Conclusion}

- In an early era in the history of human civilization, the ancient Egyptians succeeded in proving their skills in observing, analyzing and expressing various phenomena and natural events which they registered in their scenes and texts that were true reflections of their lives, thoughts, beliefs and knowledge.They had over three thousand years of sky watching, and eclipses would have been witnessed. (Park, www.academia.edu)

- "Absence of evidence is not evidence of absence!" at the base of this conception is the possibility that such phenomena may have been recorded on papyrus and not on stone. (Smith, 2007)

- In some way, this legacy has disappeared despite the fact that the inhabitants of the Nile had, without a doubt, records of this type of phenomena. (Lull, Arqueoastronomia)

- This unique solar phenomenon probably didn't have a name and is therefore referred to in terms of the way it was experienced (Smith, 2007) 
- Solar eclipses can be used accurately to date archaeological material that contains a class of texts and thus could become a remarkable method for ultimate dynastic dating. (Smith, 2007)

- Chinese and Babylonian eclipse records are believed to be over 4,000 years ago, however, recent researches have demonstrated that solar eclipses had been depicted in the mythology of the ancient Egyptians, and produced evidence that they observed solar eclipses over 4,500 years ago. (Jones, 1994 ; Steele, 2000 ; www.bibalex.org)

- Diodorus Siculus, affirmed that the astronomers of ancient Egypt were able to predict solar eclipses, in a similar vein Plutarch underlined that the ancient Egyptians explained solar eclipses by the presence of the Moon between the Sun and the earth during the hours of daytime. (science.ksc.nasa.gov)

- According to Diogenes Laetes the ancient Egyptians witnessed (and recorded) 373 solar eclipses. (after Mario, 1998)

\section{Results}

Among the well-known achievements of Egyptian culture and beyond all doubts:

1- The Ancient Egyptians were aware that the movement of the moon causes Solar Eclipses.

2- They described accurately both total and partial eclipses.

3- They registered the short duration of Solar Eclipses comparing to the long duration of Lunar Eclipses.

4- Without specific name they referred to, registered and described Solar Eclipses from the pyramid texts onward.

5- Ancient Egypt was the first civilization to register the Solar Eclipse phenomenon. 


\section{Acknowledgments}

All thanks to miss Mai Maati for her contribution.

\section{References}

- Auberg, E., 1995, "La date de conception du zodiaque du temple d'Hathor à Dendera", BIFAO vol. 95, p.1-10.

- Brewer, B., 1978-1991, Eclipse: Seattle, Earth View.

- Davies, N. \& Gardiner, A.H., 1926, The Tomb of Huy, Theban Tomb Series No. 40, EES, p. 46-53.

- Davies, N., 1903, The Rock Tombs of El Amarna, Part I - The Tomb of Meryra: Egypt Exploration Fund, p. 77-78.

- De Buck, A. \& Gardiner, Sir A. H., 1961, The Egyptian Coffin Texts vol. VII, Spells 787-1185, Chicago, p. 442-443.

- Faulkner, R.O., 1969, The Ancient Egyptian Pyramid Texts, The Clarendon Press, Oxford.

- ........., 1978, The Ancient Egyptian Coffin Texts, Vol. III, Spells 788-1185 \& Index, Aris \& Phillips Ltd., Warminster, p.161-162.

- ........, 2000, The Ancient Egyptian Book of the Dead, British Museum Press, p.123.

- Gardiner, A. H., 1928, "The Graffito from the Tomb of Pere", JEA 14 , p. 10-11.

- Gunn, B., 1916, " The Religion of the Poor in Ancient Egypt", JEA, vol. 3, 1: p. 81-94.

- Hodel- Hoenes, S., 2000, Life and Death in Ancient Egypt: Scenes from Private Tombs in New Kingdom Thebes, Cornell University Press, p. 259-260 
- Jones, A., 1994, The Place of Astronomy in Roman Egypt in Barnes, T.D., (ed), The Sciences in Greco- Roman Society, Academic Printing and Publishing, Edmonton, p.116.

- Mario, H.B., 1998, The Image of Celestial Phenomena in The Book of Coming Forth by Day: An Astronomical Philological Analysis, UMI, USA, p. 79-85, 111-115,

- Muller, P.M. \& Stephenson, F.R., 1975, "The Accelerations of the Earth and Moon from Early Astronomical Observations", in Growth Rhythms and the History of the Earth's Rotation (eds. G.D. Rosenberg and S.K. Runcorn): Wiley, p.459-533

- Neugebauer, O., 1957, The Exact Sciences in Antiquity Brown University Press, p. 66.

- Posener, G., 1975, "La piété personelle avant l'Âge Amarnien", RdE 27, p. 196, 201 and pl. 19.

- Shaw, I., 2000, The Oxford History of Ancient Egypt, OUP, p. 164.

- Schott, S., 1929-1939, Urkunden mythologischen Inhalts nebst deutscher Übersetzung, Leipzig, p.123.

- Simpson, W.K., 1972, The Literature of Ancient Egypt: An Anthology of Stories, Instructions and Poetry, Yale University Press, USA, p.238.

- Steele, J. M., 2000, Observations and Predictions of Eclipse Times by Early Astronomers, Kluwer Academic Publishers, p.101.

- Troy, L., 2017, "The Question of Evil in Ancient Egypt", JEA 98, 1: p.323-326.

\section{Internet Sites}


- Solar Eclipses in History and Mythology, Historical Observations of Solar Eclipses

\section{http://www.bibalex.org/eclipse2006/HistoricalObservationsofSolarEclipses.htm}

- Eclipse History

http://www.wral.com/how-ancient-cultures-explained-solar-eclipses/16881922

- When the dragon ate the sun: how ancient peoples interpreted solar eclipses

https://www.vox.com/culture/2017/8/18/16078886/total-solar-eclipse-folklore

- Eclipse over Amarna: Beginning of the End for Akhenaten in his City of Light?

http://www.ancient-origins.net/history-important-events/eclipse-over-amarnabeginning-end-akhenaten-his-city-light-008640

- Mackenzie, D., 1907, Egyptian Myth and Legend http://www.sacred-texts.com/egy/eml/eml15.htm

- Apep (Apophis)

http://www.ancientegyptonline.co.uk/apep.html

- Solar Eclipses in History

https://www.timeanddate.com/eclipse/solar-eclipse-history.html

- Lull, J., El eclipse solar del papiro demótico Berlín 13588, Arqueoastronomia

http://studyres.es/doc/1445677/el-eclipse-solar-del-papirodem\%C3\%B3tico-berlin-13588

- History of Eclipses

http://www.history.com/topics/history-of-eclipses 
- McMurray, W., 2003, Dating the Amarna Period in Egypt: Did a Solar Eclipse Inspire Akhenaten?

www.egyptologyforum.org/EMP/DAPE.pdf

- Park, R., The recorded Solar Eclipse of Nectanebo I

http://www.academia.edu/1863522/The_recorded_Solar_Eclipse_of_N ectanebo I

- Waldek, S., 2017, How 5 Ancient Cultures Explained Solar Eclipses

http://www.history.com/news/history-lists/how-5-ancient-culturesexplained-solar-eclipses

https://science.ksc.nasa.gov/mirrors/gsfc/omni/eclipse99/pages/traditio ns Calendars.html?utm medium=email\&utm source=govdelivery

- Smith, D. G., 2007, Total solar eclipses in Ancient Egypt - a new interpretation of some New Kingdom texts

http://www.sciencedirect.com/science/article/pii/S2090997716300682

https://brainly.in/question/24275390 Diamond ring effect:- 